\title{
Spongelike acquisition of sight vocabulary in beginning readers?
}

\author{
Morag Stuart \\ Institute of Education, University of London \\ Jackie Masterson \\ University of Essex \\ Maureen Dixon \\ University of Greenwich
}

\section{ABSTRACT}

We report two training studies designed to investigate the relation between phonological awareness, sound-to-letter mapping knowledge, and printed word learning in novice five-year-old readers. Effects of visual memory and of teaching methods are also explored.

In our first study, novice five-year-old readers able to segment initial phonemes and with good knowledge of mappings between sounds and letters learned words more easily from repeated exposure to texts. Results suggested that visual memory influenced word learning in non-segmenting but not in segmenting children. Spelling regularity did not affect ease of learning. Nouns were easier to learn than function words.

In the second study, although phonological awareness and sound-to-letter mapping knowledge still exerted a significant influence, all novice five-year-olds were able to learn words more easily if these were taught out-of-context singly on flashcards.

Results support the view that mental representations of printed words are more easily formed by beginners who are able to match at least some of the phonological segments detected in the spoken word to letters in the printed word.

\section{INTRODUCTION}

Psychological theories of reading development agree that an important aspect of learning to read involves setting up word recognition procedures that enable children to access the meanings and pronunciations of printed words; and that these procedures must be able to deal with both familiar and unfamiliar printed words. That is, children must develop a sight vocabulary of known words which can be instantly recognised and understood, and a system for translating segments of print 
to sound, to allow pronunciation of novel and unfamiliar letter strings, and thus access to their meanings. Phonological awareness and alphabet knowledge have long been seen as essential prerequisites to the phonological recoding processes necessary for access to meanings and pronunciations of unfamiliar words (Frith, 1985; Treiman and Baron, 1983). The experiments reported in the present paper investigate the development of sight vocabulary, and, in particular, the role of phonological awareness and alphabet knowledge in this aspect of development.

Surprisingly little research has been carried out into the development of sight vocabulary, which has recently been described as "remarkably spongelike" (Adams, 1990, p. 361). Given that the National Literacy Strategy (DfEE, 1998) specifies that children in the Reception year should be taught "to read on sight a range of familiar words", "to read on sight ...45 high frequency words" and "to read on sight the words from texts of appropriate difficulty", it would seem timely to put Adams' suggestion of spongelike acquisition to the test. We did this by implementing two training studies where we taught five-year-old children in their first term at school new printed vocabulary. We also prepared a computerised database of the vocabulary used in books the children were reading at school, and asked each child to read high frequency words from this vocabulary.

Early models of the development of printed word recognition procedures (Marsh, Friedman, Welch and Desberg, 1981; Frith, 1985) assumed that sight vocabulary is initially developed by rote learning of arbitrary associations between salient visual features of the printed letter string and the meaning represented by that letter string. More recently, a different view has emerged, extending the influence of phonological awareness and alphabet knowledge to sight vocabulary development. In this view, children's phonological analyses of spoken words allow formation of links between phonemic and graphemic segments. A beginning reader who can segment the initial sound of a spoken word may store the corresponding beginning letter as a salient feature in sight vocabulary; a beginning reader who can segment initial and final sounds may store initial and final letters (see, for example, Stuart and Coltheart 1988; Ehri, 1991, 1992, 1995; Rack, Hulme, Snowling and Wightman, 1994; Share, 1995). If phonological analyses and letter-sound knowledge do provide phonological underpinning for sight vocabulary, then the phonologically aware beginning reader should have an advantage in learning sight vocabulary. The logic behind this prediction is (a) links between sounds detected in spoken words and letters detected in printed words are non-arbitrary, unlike the essentially arbitrary links between printed words and their meanings; and (b) non-arbitrary links are formed more readily than arbitrary links. We investigated this prediction by comparing sight vocabulary learning in beginning readers differing in phonological awareness and sound-letter correspondence knowledge.

It is, however, unlikely that phonological awareness and sound-letter correspondence knowledge are the only influences on the ease with which beginning readers develop a sight vocabulary. Studies of reading in adult acquired dyslexic patients (e.g. Morton and Patterson, 1980) demonstrate influences of grammatical word class, with nouns showing an advantage over adjectives, verbs and function words (i.e. conjunctions, pronouns, prepositions, adverbs, etc). We therefore also manipulated word class in our first training experiment, predicting that nouns would be easier to learn than function words. This is important, as the high frequency vocabulary in children's early reading books consists almost entirely of function words. Spelling 
regularity was manipulated too, since we needed to be sure that children were acquiring sight vocabulary, and not the ability to use spelling-sound translation rules. We predicted that if the words were being learnt as sight vocabulary, then words with irregular spellings should be as easy to learn as words with regular spellings.

Teaching conditions are a further likely source of influence on sight vocabulary development. Our first training experiment was designed to approximate as closely as possible the teaching conditions pertaining in the children's school, which put into practice many of the ideas subsumed under the apprenticeship approach to reading (Waterland, 1985). ${ }^{1}$ This approach is an offshoot of the whole language approach advocated by Goodman (1967), which suggests that teachers should encourage children to read for meaning, to predict and draw inferences from the text which they sample to confirm their predictions. In a later publication (Goodman, 1986), teachers are told to "cultivate the alphabetic principle, not specific phonics". Waterland (1985) suggests that children should learn to read by repeatedly sharing books with an adult, who at first takes responsibility for the reading, gradually withdrawing support as the child develops sufficient independence to be able to read alone. Children are encouraged to predict what will happen next, and to check their predictions against the text, using initial letters of words as a guide. This was operationalised in the first training experiment by preparing two illustrated books containing the target words to be learned, which were repeatedly read with the children.

Previous research indicates that there may be problems in using illustrated texts and teaching words in context. For example, studies by Samuels (1967), Harzem, Lee and Miles (1976) and Singer, Samuels and Spiroff (1973-4) suggest that pictures divert attention away from the printed word and thus impede word learning. Our second experiment therefore compared three teaching conditions: sight vocabulary learning through (a) repeated reading of illustrated texts, (b) repeated reading of illustrated texts with prior presentation of each target word, and (c) repeated presentation of single words on flashcards.

\section{FIRST TRAINING EXPERIMENT}

\section{Method}

\section{Participants}

Participants were five-year-olds from two classes of new entrants to the Reception class in an Inner City primary school. All children were screened using the British Ability Scales Single Word Reading Test (Elliott, Murray and Pearson, 1983). Children reading no words on this test were given a test of Initial Sound Segmentation and Sound-to-letter Matching (Stuart, 1995a). Scores from this test

\footnotetext{
1 Inevitably, in a controlled experiment, we could not absolutely reproduce the teaching procedures advocated in the apprenticeship approach, which involves exposing children to numerous books, not just two. However, we took care to check that our findings (that five-year-old beginners require rather a lot of repetition to acquire new sight vocabulary) were not limited to the particular experimental situation we placed the children in. We did this by also asking the children to read words which they had encountered very frequently in the numerous books to which they were exposed in school. Their performance in reading this high frequency vocabulary (reported in the Results section) was extremely poor, supporting the view that these young beginners do not soak up sight vocabulary like sponges.
} 
were used to form two groups of ten children. The good graphophonic skills group (henceforward GP+) contained children with good segmentation skills and good knowledge of sound-to-letter mappings; the poor graphophonic skills group (henceforward GP-) contained children with little or no segmentation ability and little or no knowledge of sound-to-letter mappings. Children were also given the Goulandris Visual Memory Test (Goulandris and Snowling, 1991).

The two subject groups did not differ in their chronological age (GP+, mean age 5.16, s.d. 0.32; GP-, mean age 5.17, s.d. 0.32; $\mathrm{t}=0.07, \mathrm{p}=0.95$ ), nor in their visual memory ability (GP + , mean 5.3, s.d. 1.70; GP-, mean 5.78, s.d. 1.64, t $=0.38$, $\mathrm{p}=0.54)$.

\section{Materials}

Two books were made to read with the children, with lively illustrations of each target word. The text was printed in Univers font size 36. 16 target words (leopard, haddock, canoe, lorry, glove, scarf, onion, camel, anyone, myself, everybody, someone, because, nobody, quite, enough) were trained in nine training sessions; each book contained eight of the targets, which appeared four times in a book, making a total of 36 exposures per word over the entire training period. Target words were printed in red to make them prominent in the text. The target words were not in the children's school reading vocabulary, and at pretest no child could read any. Eight were nouns and eight were function words; in each word class category, four had irregular and four had regular spellings. Regular and irregular nouns and function words were equally divided between the two books. Words did not differ in letter length across word class or spelling regularity $(\mathrm{F}=1, \mathrm{p}=0.43)$. The number of words per page did not differ significantly between the two books $(t=0.69, \mathrm{p}=0.49)$. Target nouns were less likely to appear alone on a page than target function words $(\mathrm{t}=3.51$, $\mathrm{p}=0.001$ ).

A set of 16 flashcards was made with each target word printed singly in red in Univers font size 36. A set of 11 flashcards (henceforth 'control words') was made with a selection of non-target words repeated from 4 to 28 times per book.

The Initial Sound Segmentation and Sound-to-Letter Matching test consists of 24 pictures. Each picture name begins with a different sound, mapping onto the 24 letters of the alphabet that remain when $\mathrm{q}$ and $\mathrm{x}$ are excluded. There are 24 letter cards containing each target letter with two distractors. If children do not give the correct first sound for any picture name, this is supplied for them. All children are then asked to choose the letter representing that sound on the relevant letter card.

In the Goulandris Visual Memory test, children are exposed for ten seconds to cards printed with sequences of from two to four Greek letters. After each sequence is presented, children are shown the individual Greek letters from that sequence, plus two distractors, and asked to recreate the sequence. There are 13 trials in all: one practice trial, six trials requiring immediate recall and six where recall follows a tensecond delay.

\section{Screening, pre-testing, training and post-testing schedule}

Screening tests were given by one member of the research team and results of these tests were not revealed to the trainer, who was thus 'blind' to which children were 
expected to learn easily and which to find learning difficult. Screening and pre-testing took place during October and November, in the children's first term at school. Nine training sessions took place during November and December, with an immediate recall post-test after each training session, in which children were shown each word in random order and asked to name it. On completion of training in December, and at a delayed post-test at the end of January, children were tested on both recall and recognition: for the recognition test, flashcards of the words were laid on the table and children were asked to point to words named for them.

\section{Training procedure and instructions}

Children were taken in pairs out of the classroom to a quiet place. They sat one on each side of the trainer to read the books with her. Children were told: "Do you know why I've come to your school? Because I want to find out how easy it is for you to learn to read some words. I've made these special books for us to read together, and the words I want you to try to learn are in the books. Shall we have a look? I'll read the book, and you look at the words while I read. The ones I want you to remember are the red ones". The trainer began to read to the children, pointing to each word as she read it. When the first red word was reached, she said: "Oh, look, here's one of the red words for you to learn. This word says------. Can you read it?" Each child repeated the word while the trainer pointed to it. The same procedure was repeated as each red word was encountered. Once both books had been read, children were tested individually on the 16 red flashcards. The two immediately subsequent training sessions followed the same general procedure. During sessions four to six the trainer implanted the idea that it was useful to pay attention to at least some of the letters if you wanted to be able to remember words. For the first two appearances of each red word, the trainer said, for example, "Now, how are we going to remember that that one says leopard'? Oh, look, it's got an L at the beginning, /l/ for leopard. Shall we try to remember that? $L, / l /$, for leopard".

Children enjoyed the training sessions and were attentive and interested throughout, making frequent comments on the pictures in each book, and taking an interest in the new vocabulary ${ }^{2}$ (i.e. 'haddock' for fish) they were learning.

\section{Results}

\section{(a) Spongelike acquisition of sight vocabulary?}

The overall rate of word learning was very low. After 36 exposures, the overall mean was 4.95 (s.d. 3.09); no child scored more than 12/16, and two children were unable to name any of the target words correctly.

Although the 11 control words were seen from 36 to 252 times during training, there was no significant difference in reading these words from pre-test to post-test:

\footnotetext{
${ }^{2}$ It might be commented that the words we were teaching the children were rather esoteric and difficult for five-year-olds. We should just like to point out that they were no more esoteric and difficult than many of the words in the children's school reading vocabulary (e.g. cacophony, kingfisher, laundry, nectar, although, thought) and 'haddock' really was the only word which was unfamiliar in spoken language to many of the children.
} 
pre-test mean, 0.45, s.d. 0.94; post-test mean, 0.60, s.d. 1.57; $\mathrm{t}=0.83, \mathrm{p}=0.42$. Also, to assess the ecological validity of our training, we gave each child a list of high frequency words from their own personal reading vocabulary to read aloud. The mean number of different words they had met in their reading during their first term at school was 125.9 (s.d. 57.9, range 39-277). The mean number of words which appeared more than 20 times in any child's vocabulary pool was 3.68 (s.d. 3.93, range $0-14$ ). Given the modest results of the training experiment, where children were exposed 36 times to the training stimuli, it is not surprising that there was little correct naming of words from this high frequency vocabulary: mean score 1.26 words (s.d. 2.4, range $0-10$ ). These results suggest that beginning readers need considerably more repetition of printed vocabulary than typically exists in the reading material to which they are introduced if they are reliably to recognise and name words presented out of context. Children also benefit from being given clear instructions to try to remember words.

\section{(b) Influences of phonological awareness and alphabet knowledge}

Although the overall learning rate was low, the predicted differences in learning between GP + and GP- groups were found, with GP + children showing better learning throughout the training period and better retention at post-testing than GPchildren (see Table 1).

Table 1. Experiment 1. Mean scores and standard deviations (s.d.) after 12, 24 and 36 exposures and on immediate and delayed post-tests, by children with good $(\mathrm{GP}+)$ and poor (GP-) graphophonic skills.

\begin{tabular}{lcccr}
\hline & \multicolumn{2}{c}{ GP + group } & \multicolumn{2}{c}{ GP- group } \\
& Mean & S.d. & Mean & s.d. \\
\hline 12 exposures & 1.1 & 1.3 & 0.1 & 0.3 \\
24 exposures & 3.4 & 3.0 & 0.8 & 1.6 \\
36 exposures & 6.8 & 2.6 & 3.1 & 2.4 \\
Recognition test & 7.3 & 3.1 & 4.0 & 2.6 \\
Delayed recognition test & 7.1 & 3.0 & 4.2 & 3.1 \\
Delayed recall test & 4.8 & 2.4 & 2.4 & 2.3 \\
& & & & \\
\hline
\end{tabular}

These differences were explored by t-tests comparing words learnt after 12, 24, and 36 exposures, on the immediate recognition post-test, and on the one month delay recognition and recall post-tests, by GP + and GP-groups. Significant main effects of group were found after 12 exposures $[\mathrm{t}(18)=2.39, \mathrm{p}=0.038], 24$ exposures $[\mathrm{t}(18)=2.4, \mathrm{p}=0.028], 36$ exposures $[\mathrm{t}(18)=3.31, \mathrm{p}=0.004]$, on immediate recognition post-test $[\mathrm{t}(18)=2.59, \mathrm{p}=0.018]$, on one month delay recognition post-test $[\mathrm{t}(18)=2.12, \mathrm{p}=0.048]$, and on one month delay recall post-test $[\mathrm{t}(18)=2.28, \mathrm{p}=0.035]$. These results demonstrate a clear influence of phonological awareness and alphabet knowledge on sight vocabulary learning. 


\section{(c) Influences of visual memory}

Possible influences of visual memory were explored by examining correlations between visual memory scores and word learning after 12, 24 and 36 trials, in GP + and GP-groups. As shown in Table 2, visual memory scores were not associated with word learning at any point in the GP + group. However, after 36 trials, when the GP-group were beginning to remember some of the words, there was a highly significant correlation $(r=0.79)$ between visual memory scores and word learning in the GP-group. These results suggest different sources of influence may be operating on the learning of the two subgroups. For the GP- children the learning task seems indeed to have been one of trying to commit sequences of unfamiliar abstract printed items to memory, precisely the ability tested in the Goulandris Visual Memory test. Thus it is not surprising that the visual memory test was significantly correlated with their learning after 36 exposures. Interestingly, the two subgroups did not differ significantly in their visual memory scores, which reinforces the view that visual memory is a strategy of last resort for those who have no other available.

Table 2. Experiment 1. Correlations between visual memory scores and word learning, by children with good $(\mathrm{GP}+)$ and poor $(\mathrm{GP}-)$ graphophonic skills.

\begin{tabular}{lccc}
\hline & 12 exposures & 24 exposures & 36 exposures \\
\hline GP + group & -0.12 & -0.07 & -0.11 \\
GP- group & 0.28 & 0.30 & $0.79^{* *}$ \\
\hline
\end{tabular}

$* *$ significant at $\mathrm{p}<0.01$

\section{(d) Durability of learning}

Of interest also is the question of durability of learning: was the hard-won learning of the GP- subgroup as durable as that of the GP + subgroup? Mean loss by each subgroup from the end of training to one-month post-tests is shown in Table 3. Huck and McLean (1975) caution against using repeated measures ANOVA to analyse pretest-posttest differences of this kind; we therefore calculated loss scores for each participant which we analysed using simple ANOVA and one-sample t-tests. There were no significant effects of group on loss in either recognition or recall [recognition: $\mathrm{F}(1,18)=0.37$, n.s.; recall: $\mathrm{F}(1,18)=3.79$, $\mathrm{p}>0.05$ ]. There was no significant loss in recognition scores from immediate to delayed posttest $[\mathrm{t}(19)=0]$, but a significant loss in recall scores $[\mathrm{t}(19)=3.78, \mathrm{p}<0.005]$. The fact that recognition suffers no loss over time suggests that it requires a less well-specified representation than does recall.

\section{(e) Influences of word class and spelling regularity}

Scores for correct reading of regular and irregular nouns and function words after 36 exposures (see Table 4) were analysed by subject group in a repeated measures ANOVA. There was a significant effect of group $[\mathrm{F}(1,18)=10.95, \mathrm{p}=0.004]$, with $\mathrm{GP}+$ children outperforming $\mathrm{GP}-$; a significant effect of word type $[\mathrm{F}(1,18)=12.5$, 
Table 3. Experiment 1. Mean loss and standard deviations (s.d.) in recognition and recall scores at delayed posttest, by children with good $(\mathrm{GP}+)$ and poor (GP-) graphophonic skills.

\begin{tabular}{llcl}
\hline & & Recognition & Recall \\
\hline GP+ group & Mean & 0.2 & 2.0 \\
& s.d. & 1.75 & 1.49 \\
GP- group & Mean & -0.2 & 0.7 \\
& s.d. & 0.7 & 1.49
\end{tabular}

$\mathrm{p}=0.002]$, with nouns better remembered than function words; and a significant interaction between group and word type $[\mathrm{F}(1,18)=6.83, \mathrm{p}=0.018]$ : $\mathrm{GP}+$ children were significantly more likely than GP- children to read more nouns than function words correctly. This interaction is probably due to floor effects in the GPgroup, and therefore not of theoretical interest. There was no effect of regularity $[F(1,18)=0.68, p=0.42]$ and no group by regularity interaction $[F(1,18)=0.24$, $\mathrm{p}=0.63]$. This is as we predicted: even though the GP + group were able to use their knowledge and understanding of sounds and letters and the fact that the two could be related as aids to remembering the target words, their knowledge was too restricted to be of use in translating segments of print to sound.

Table 4. Experiment 1. Mean scores and standard deviations (s.d.) for reading regular and irregular nouns and function words by children with good $(\mathrm{GP}+)$ and poor (GP-) graphophonic skills, after 36 exposures.

\begin{tabular}{|c|c|c|c|c|c|}
\hline & & \multicolumn{2}{|c|}{ Nouns } & \multicolumn{2}{|c|}{ Function words } \\
\hline & & Regular & Irregular & Regular & Irregular \\
\hline \multirow[t]{2}{*}{ GP+ } & Mean & 2.3 & 2.1 & 1.3 & 1.1 \\
\hline & s.d. & 0.82 & 0.74 & 0.82 & 0.88 \\
\hline \multirow[t]{2}{*}{ GP- } & Mean & 1.1 & 0.6 & 0.5 & 0.9 \\
\hline & s.d. & 1.2 & 0.69 & 0.53 & 0.99 \\
\hline
\end{tabular}

\section{Discussion}

Despite the disappointing rate of learning in this first training experiment, clear differences were obtained between children according to their graphophonic skills. At all points tested, children with good graphophonic skills had learned significantly more words than those without these skills. No significant effects of regularity were found, suggesting that none of the children were yet able to decode unfamiliar words. These results provide support for the view that phonological analysis ability and alphabetic knowledge provide a good foundation for constructing mental representations of printed words (Ehri, 1991, 1992, 1995; Stuart and Coltheart, 1988; Rack et al, 1994; Stuart, 1995b; Share, 1995). Stuart and Coltheart also suggested that visually-based logographic reading may exist, but only as a default strategy for those phonologically unaware children with no other options available. This also receives some support from the present study, where visual memory was significantly 
correlated with GP- children's word learning after 36 exposures, and never correlated with that of GP + children, even though the two groups did not differ in visual memory scores.

It also seems clear that the five-year-olds in the present study needed considerably more repetition of vocabulary than they typically received in their reading material in order to develop sight vocabulary. We undertook a second training experiment to discover the extent to which this was a consequence of the training conditions pertaining both in our first experiment and in the children's school, where there was little or no emphasis on the importance of isolated word recognition.

\section{SECOND TRAINING EXPERIMENT}

The second training experiment contrasted three training conditions: flashcard (learning isolated words on flashcards), book (learning words in illustrated context) and mixed (learning words in illustrated context with prior presentation of the isolated word). It was predicted that the flashcard condition would prove the most efficient, both in terms of amount of learning and training time. Performance in the mixed condition was expected to fall between the flashcard condition and the book condition.

Children's recall was tested under three conditions: presentation of the isolated word, word-picture matching, and presentation of the word in sentence context. The word-picture matching condition was included because a training experiment by Ehri and Roberts (1977) found that orthographic forms of words are best learned in isolation, but word meanings are best learned in context. However, Ehri and Roberts taught children eight homophone pairs (e.g. 'which - witch'), and this may underlie their finding that context aids learning of word meanings. In our experiment, with no necessity to distinguish between words that sound the same but have different meanings, we expected the flashcard trained group also to do better on the wordpicture matching task that assessed access to word meaning. The sentence context condition was included because a training study by Nemko (1984) found that training conditions affected likelihood of recall under different recall conditions: words trained in isolation were better recalled when presented in isolation; words trained in context were better recalled in context. Since in real world conditions word reading takes place in context, we felt it was important to see whether Nemko's findings would be replicated, with flashcard trained children recalling words presented in isolation better than those presented in a sentence context, and booktrained children showing the opposite pattern. However, we expected that flashcard trained children would show superior recall in all conditions. Both the above expectations were based in a belief in the prime importance of word recognition to reading for meaning and to reading connected text.

\section{Method}

Participants

Two classes of five-year-olds in two inner city primary schools were given the British Ability Scales Single Word Reading Test. Complete non-readers were then screened 
using the Initial Sound Segmentation and Sound-to-Letter Matching test. Three training groups of ten children were formed on the basis of scores on this test and school attended. As far as possible, equal numbers of GP + and GP-children were in each training group. One GP- child in the flashcard training group caught chicken pox and failed to complete the experiment; her data were not included in the analyses. In the mixed training group, there were more GP + (6) than GP- (4) children. Nevertheless, as shown in Table 5, there were no significant differences between training groups in initial sound segmentation scores $[\mathrm{F}(2,27)=0.001$, $\mathrm{p}=0.99]$, or sound-to-letter correspondence knowledge $[\mathrm{F}(2,27)=0.90, \mathrm{p}=0.42]$. As before, the trainer was 'blind' to the composition of the training groups.

Table 5. Experiment 2. Graphophonic skills of the children by training condition at the start of the study.

\begin{tabular}{|c|c|c|c|c|c|c|}
\hline & \multicolumn{6}{|c|}{ Training condition } \\
\hline & \multicolumn{2}{|c|}{ Flashcard } & \multicolumn{2}{|c|}{ Mixed } & \multicolumn{2}{|c|}{ Book } \\
\hline & Mean & s.d. & Mean & s.d. & Mean & s.d. \\
\hline Sound Segmentation Test & 4.80 & 5.05 & 4.90 & 5.13 & 4.90 & 5.15 \\
\hline Letter Sounds Test & 7.20 & 2.53 & 5.80 & 2.86 & 7.50 & 3.57 \\
\hline
\end{tabular}

\section{Materials}

Four rhyming question-and-answer books were made with lively illustrations accompanying each target word. The target words (the eight nouns from the first training experiment) appeared once per book, printed in red, in Univers font size 36. Two sets of eight flashcards of the target words were also used, printed in red, in Univers font size 36. For post-testing a set of pictures illustrating each target word was used, and a set of eight sentences taken from the books but printed entirely in black, with one target word per sentence.

\section{Training schedule, training conditions and procedure}

Screening took place at the end of February, and training was carried out during March and April, with two training sessions per child per week until eight training sessions had been given, with all four books read or each flashcard presented four times in each session ( 32 exposures of each word). Each child was pre-tested on the eight target words before the first training session. No child could read any of the words.

In all three training conditions (flashcard, book and mixed) children were instructed: "Do you know why I've come to your school? Because I want to find out how easy it is for you to learn to read some words. I've got eight words here for you to learn to read, but first I want to find out if you know any of them already. Do you know what this one says? ... Or this? ... Well those are good ones to learn, aren't they? because you don't know them yet".

Children in the flashcard group were then instructed: "Now I'm going to tell you what the words are. This one says-----. Do you know what a----- is? That's right, 
it's a - - - isn't it?" (or: "It's a - -..." plus conversation with the child to make sure the word's meaning was understood). When all eight words had been shown, named and discussed, the cards were shuffled and the child instructed: "Let's have another look at them. What did this one say?" The trainer hesitated momentarily to give the child chance to respond, before supplying the word for the child. This was repeated until each word had been shown and named, either by or for the child, four times.

Children in the book group were instructed: "I've got some books here with the words in for you to learn. Shall we have a look? I'll read the book and you look at the words while I read. The ones I want you to remember are the red words". As in the first training experiment, the trainer stopped at each red word and said, "Oh, look, here's one of the red words for you to learn". She then pointed to the red word and said: "This word says ---.-. Do you know what a ----- is?" (Unfamiliar words were explained and discussed as with the flashcard group children). The trainer then asked: "Can you read it?" and got the child to repeat the word while she pointed to it. All four books were read each session, so that each target word was exposed four times in each session.

The mixed group were given the same instructions as the book group, except that the trainer put a flashcard printed with the next-appearing red word (e.g. 'scarf') on to each question page (e.g. "What's in the pot?"), and the child was encouraged to look at and repeat or read it before the page was turned to reveal the picture (e.g. "A scarf worn by a Scot").

The measure of context-free word recall was the number of words correctly named by each child when words were presented singly on flashcards. The measure of comprehension was the number of target words correctly matched to pictures, and the measure of word recall in (sentence) context was number of target words correctly read from the sentence cards. These three measures were taken immediately after the final training session for each child.

Each training session with each child was timed. Two measures of training time were used in subsequent data analysis: the average time taken for each child over all eight training sessions, and the duration of the final training session.

\section{Results and discussion}

Data were analysed to see if there were school effects; as there was no difference between schools, the results were summed across children from both schools (see Table 6).

\section{(a) Context-free word recall}

The number of words learned by each child at the end of training was entered as the dependent variable in a two-factor ANOVA (training group $\times$ graphophonic skills group). There was a significant main effect of training group $[\mathrm{F}(2,28)=6.42$, $\mathrm{p}=0.006]$ and of graphophonic skills group $[\mathrm{F},(1,28)=6.12, \mathrm{p}=0.021]$. Planned comparisons using least significant difference showed that the flashcard group had learned significantly more words than the book group and the mixed group.

It had been anticipated that performance of the mixed group, who saw words first without pictures, would be intermediate between that of the flashcard group, who 
Table 6. Experiment 2. Mean scores and standard deviations (s.d.) by training condition and by graphophonic skills group, at the end of the study.

\begin{tabular}{|c|c|c|c|c|c|c|}
\hline & \multicolumn{6}{|c|}{ Training condition } \\
\hline & \multicolumn{2}{|c|}{ Flashcard } & \multicolumn{2}{|c|}{ Mixed } & \multicolumn{2}{|c|}{ Book } \\
\hline & Mean & s.d. & Mean & s.d. & Mean & s.d. \\
\hline Context free recall & 6.67 & 2.18 & 3.60 & 3.06 & 2.90 & 2.42 \\
\hline Comprehension & 6.56 & 1.67 & 3.11 & 3.02 & 2.60 & 2.63 \\
\hline Recall in sentence & 5.33 & 2.39 & 2.11 & 2.76 & 2.20 & 2.86 \\
\hline Average session time (mins.) & 6.53 & 1.97 & 13.65 & 1.42 & 12.78 & 1.53 \\
\hline \multirow[t]{4}{*}{ Final session time (mins.) } & 7.33 & 2.18 & 12.9 & 2.42 & 12.50 & 2.41 \\
\hline & \multicolumn{6}{|c|}{ Graphophonic skills } \\
\hline & \multicolumn{3}{|c|}{ GP + (good $)$} & & \multicolumn{2}{|c|}{ GP- (poor) } \\
\hline & & Mean & s.d. & & Mean & s.d. \\
\hline Context free recall & & 5.31 & 2.79 & & 3.08 & 2.84 \\
\hline Comprehension & & 5.13 & 2.87 & & 2.77 & 2.71 \\
\hline Recall in sentence & & 4.27 & 3.06 & & 1.92 & 2.46 \\
\hline Average session time (mins.) & & 11.14 & 4.05 & & 11.15 & 2.97 \\
\hline Final session time (mins.) & & 10.81 & 3.73 & & 11.31 & 3.07 \\
\hline
\end{tabular}

always saw words without pictures, and that of the book group, who never saw words without pictures. There was both a significant linear trend in this direction $(\mathrm{t}=2.65, \mathrm{p}<0.02)$ and a significant quadratic trend $(\mathrm{t}=2.50, \mathrm{p}<0.02)$, reflecting the larger advantage for flashcards over mixed training.

\section{(b) Comprehension}

The number of correct matches between target word and picture was entered as the dependent variable in a two-factor ANOVA (training group $\times$ graphophonic skills group). The results of this analysis replicated that of context-free word recall. There was a significant main effect of training group $[\mathrm{F}(2,27)=8.28, \mathrm{p}=0.002]$, and of graphophonic skills group $[\mathrm{F}(1,27)=7.12, \mathrm{p}=0.014]$. Planned comparisons again showed that the flashcard group performed better than both the book group and the mixed group. These results suggest that, as predicted, the main factor influencing children's comprehension was their ability to recognise and name the printed words. Children in the book and mixed groups had learned fewer words and were therefore unable to perform the word-picture matching task.

\section{(c) Word recall in sentence context}

As in the two previous analyses, there was a significant main effect of training group $[\mathrm{F}(2,28)=4.87, \mathrm{p}<0.02]$ and of graphophonic skills group $[\mathrm{F}(1,27)=5.49$, $\mathrm{p}<0.03$ ]. Planned comparisons again showed that the flashcard group performed significantly better than the book group and the mixed group. As predicted, isolated word recognition training produced better reading of words in context. 


\section{(d) Training time}

When average training time was entered as the dependent variable in a two-factor ANOVA (training group $\times$ graphophonic skills group) there was a significant effect of training group $[\mathrm{F}(2,28)=50.38, \mathrm{p}<0.0001)$ but no effect of graphophonic skills group. Planned comparisons showed significantly shorter training time for the flashcard group compared to both the book group and the mixed group.

These results were replicated when duration of the final training session was entered as the dependent variable: main effect of training group $[\mathrm{F}(12,28)=14.3$, $\mathrm{p}<0.0001$ ) with shorter sessions for the flashcard group than the book group or the mixed group, and no effect of graphophonic skills group.

The results show clearly that teaching children new vocabulary by using flashcards leads to more successful acquisition of the vocabulary and takes less time than teaching children new vocabulary by repeated reading of books. In the present experiment this seems to have been achieved with no detriment either to the comprehension of children taught with flashcards, or to their ability to recognise words in continuous text. Children's graphophonic skills influence speed of sight vocabulary acquisition regardless of method of exposure to new vocabulary.

\section{GENERAL DISCUSSION}

Our results show clearly that sight vocabulary development in beginning readers is influenced by characteristics of the child, of the words to be learned, and of the teaching conditions.

For the young and completely inexperienced five-year-old beginners in our two training experiments, acquisition of new sight vocabulary required in most cases rather more repetition than we gave in our training, and certainly more than they were likely to experience in their reading at school and at home. From results in the present study, in which $60 \%$ of children in the flashcard trained group in the second training experiment learned all eight words after 32 exposures, it seems that using flashcards to teach sight vocabulary is an excellent way of focusing children's attention on the printed words and providing sufficient repetition, without detriment to understanding or ability to read words in context.

The children who did best in both training experiments were those who were phonologically aware and who also knew how speech sounds could be represented by letters; i.e. those with good graphophonic skills. These results reinforce the prevailing view from much recent research, that teachers should be alert to children's phonological analysis abilities and alphabetic knowledge, and seek to develop these in children lacking them on school entry.

The learning task also needs to be made explicit to the children, and they need to be given hints as to how it can be accomplished. In the first training experiment, children were clearly instructed to try to remember the target words, and these instructions were reinforced by testing children's recall after each training session. After the first 12 exposures, they were also repeatedly told that paying attention to certain letters was a useful strategy to apply. All but two children learned some words under these conditions, whereas there was almost no learning of control words, even though some of these occurred much more frequently than the target words. Also, children 
performed dismally when asked to read high frequency words from their own reading vocabulary experienced under classroom conditions (i.e. with no instruction to try to remember words, and no hints as to useful strategies by which this might be achieved).

The results obtained are broadly compatible with the view that, at the very beginning of learning to read, children with good graphophonic skills are able to use these as the basis for their mental representations of printed words.

The learning conditions to which the children were exposed in their school involved repeated reading of books in partnership with a helpful adult. How might a naive five-year-old reader acquire sight vocabulary from this experience? As we observed in our training experiments, when children engage in repeated reading of texts, they quickly memorise the text and learn to recite it accurately to the relevant picture cue. Children with good graphophonic skills, however, can do more than this. As each new page is turned, the picture evokes a rote memory of the spoken form of the text, which the child can analyse into words; thus, the child has the sound of a word in her head as she comes to the printed word on the page. The words in her head can be further analysed into onset and rime segments (Treiman, 1985) and into initial (and possibly also final) phoneme segments (Stuart, 1990). Thus, the child can use her knowledge of sound-to-letter correspondences as a check on whether the word she is saying aloud does correspond to the word printed on the page. Over time (and with multiple repetitions!) this helps the child to store frequently repeated words as sight vocabulary, with partial links to phonology, as well as arbitrary links to semantics. Sub-word level correspondences between phonology and orthography thus underpin correspondences at the word level, and provide a principled motivation for including certain orthographic features into the stored representations of each printed word. The child with rudimentary or no graphophonic skills cannot make systematic links between orthography and phonology, and will be left either struggling to build representations that link arbitrarily to pre-existing semantic representations, that are not anchored in prior analysis of existing phonological representations, or, worse, will fail to grasp that this is a requirement of the task of learning to read, which will be interpreted as requiring memorisation of texts which can be recited appropriately to picture cues.

The task of acquiring sight vocabulary from repeated reading of text is thus easier for the child with good graphophonic skills, but the task itself is more difficult than that of acquiring sight vocabulary from exposure to flashcards. In the flashcard task, not only is the child's attention inevitably focused on the words to be learned, but a pre-existing concept of a word is not necessary to success. Printed words are presented singly, and a single spoken word response is given. This might serve to induce the concept of a word in children who previously lacked it, as well as the concept of there being a one-to-one correspondence between printed and spoken forms.

Our results thus further underline the importance of phonological awareness and knowledge about the alphabet to successful initiation into printed word recognition, by extending their influence to include sight vocabulary development as well as the establishment of phonological recoding procedures.

\section{Acknowledgements}

The research reported in this paper was undertaken with the support of ESRC Grant No. R000 234380. We should like to thank the teachers and children who 
participated for their willing cooperation, and Liz Poole for undertaking the training in our second experiment. We also thank A. and C. Black, Mammoth Books, Oxford University Press, Ginn and Penguin Books, who donated materials to our database project; and Reed International, Lion Books, Nelson, Ladybird, Walker Books and Longman, for allowing us access to their texts.

\section{REFERENCES}

ADAMS, M.J. (1990) Beginning to read: thinking and learning about print. Cambridge, Mass.: MIT Press. DOWNing, J. and OLIVER, P. (1973-1974) The child's conception of a word. Reading Research Quarterly, 9, 568-582.

DfEe (1998) The National Literacy Strategy: Framework for Teaching. London: Department for Education and Employment.

EHRI, L.C. (1991) Development of the ability to read words. In R. Barr, M. Kamil, P. Mosenthal and P. Pearson (Eds.) Handbook of Reading Research, Volume II. New York: Longman.

EHRI, L.C. (1992) Reconceptualizing the development of sight word reading and its relationship to recoding.

In P.B. Gough, L.C. Ehri and R. Treiman (Eds.) Reading Acquisition. Hillsdale, N.J.: Erlbaum.

EHRI, L.C. (1995) Phases of development in learning to read words by sight. Journal of Research in Reading, $18,116-125$.

EHRI, L.C. and ROBERTS, K.T. (1979) Do beginners learn printed words better in context or in isolation? Child Development, 50, 675-685.

EHRI, L.C. and SWEET, J. (1991) Finger-point reading of memorized text: What enables beginners to process the print? Reading Research Quarterly, 26, 442-462.

ELliotT, C.D., MURRAY, D.J. and PEARSON, L.S. (1983) British Ability Scales. Windsor, Berks: NFER-Nelson. FRITH, U. (1985) Beneath the surface of developmental dyslexia. In K.E. Patterson, J.C. Marshall and

M. Coltheart (Eds.) Surface Dyslexia. London: Erlbaum.

Goodman, K.S. (1967) Reading: A psycholinguistic guessing game. Journal of the Reading Specialist, 6, $126-135$.

GOOdman, K.S. (1986) What's whole in whole language? Portsmouth, NH: Heinemann.

GOULANDRIS, N.K. and SNOWLING, M. (1991) Visual memory deficits: A plausible cause of developmental dyslexia? Evidence from a single case study. Cognitive Neuropsychology, 8, 127-154.

HARZEM, P., LEE, I. and MILES, T.R. (1976) The effects of pictures on learning to read. British Journal of Educational Psychology, 46, 318-322.

HUCK, S.W. and MCLEAN, R.A. (1975) Using a repeated measures ANOVA to analyse the data from a pretestposttest design: A potentially confusing task. Psychological Bulletin, 82, 511-518.

MARSH, G., FRIEDMAN, M., WELCH, V. AND DESBERG, P. (1981) A cognitive-developmental theory of reading acquisition. In G.E. McKinnon and T.G.Waller (Eds.) Reading Research: Advances in Theory and Practice. Volume 3. New York: Academic Press.

MORTON, J. and PATTERSON, K. (1980) A new attempt at an interpretation, or, an attempt at a new interpretation. In M. Coltheart, K. Patterson and J.C. Marshall (Eds.) Deep Dyslexia. London: Routledge and Kegan Paul.

NEMKO, B. (1984) Context versus isolation: Another look at beginning readers. Reading Research Quarterly, $19,461-467$.

RACK, J., HUlme, C., SNOWling, M. and Wightman, J. (1994) The role of phonology in young children learning to read words: The direct-mapping hypothesis. Journal of Experimental Child Psychology, 39, $161-181$.

SAMUELS, S.J. (1967) Attentional process in reading: The effect of pictures on the acquisition of reading responses. Journal of Educational Psychology, 58, 337-342.

SHARE, D.L. (1995) Phonological recoding and self-teaching: sine qua non of reading acquisition. Cognition, 55, 151-218.

SINGER, H., SAMUELS, S.J. and SPIROFF, J. (1973-1974) The effect of pictures and contextual conditions on learning responses to printed words. Reading Research Quarterly, 9, 555-567.

STUART, M. (1990) Factors influencing word recognition in pre-reading children. British Journal of Psychology, 81, 135-146. 
StUART, M. (1995a) Prediction and qualitative assessment of five- and six-year old children's reading: A longitudinal study. British Journal of Educational Psychology, 65, 287-296.

STUART, M. (1995b) Through printed words to meaning: Issues of transparency. Journal of Research in Reading, 18, 126-131.

StUART, M. and COltheArt, M. (1988) Does reading develop in a sequence of stages? Cognition, 30, 139-181.

TREIMAN, R. (1985) Onsets and rimes as units of spoken syllables: Evidence from children. Journal of Experimental Child Psychology, 39, 161-181.

TREIMAN, R. and BARON, J. (1983) Phonemic analysis training helps children benefit from spelling-sound rules. Memory and Cognition, 11, 382-389.

waterland, L. (1985) Read With me: An Apprenticeship Approach to Reading. Stroud, England: Thimble Press.

Address for correspondence: DR MORAG STUART, Psychology and Special Needs, Institute of Education, University of London, 25 Woburn Square, London, WC1H 0AA, UK. Email: m.stuart@ioe.ac.uk 
Copyright $\odot 2003$ EBSCO Publishing 
Copyright of Journal of Research in Reading is the property of Wiley-Blackwell and its content may not be copied or emailed to multiple sites or posted to a listserv without the copyright holder's express written permission. However, users may print, download, or email articles for individual use. 